\title{
Materials and Textile Architecture Analyses for Mechanical Counter-Pressure Space Suits using Active Materials
}

\author{
Bradley Holschuh ${ }^{1}$, Edward Obropta $^{2}$, Leah Buechley ${ }^{3}$, and Dava Newman ${ }^{4}$ \\ Massachusetts Institute of Technology, Cambridge, MA 02139
}

\begin{abstract}
Mechanical counter-pressure (MCP) space suits have the potential to improve the mobility of astronauts as they conduct planetary exploration activities. MCP suits differ from traditional gas-pressurized space suits by applying surface pressure to the wearer using tight-fitting materials rather than pressurized gas, and represent a fundamental change in space suit design. However, the underlying technologies required to provide uniform compression in a MCP garment at sufficient pressures for space exploration have not yet been perfected, and donning and doffing a MCP suit remains a significant challenge. This research effort focuses on the novel use of active material technologies to produce a garment with controllable compression capabilities (up to $30 \mathrm{kPa}$ ) to address these problems. We provide a comparative study of active materials and textile architectures for MCP applications; concept active material compression textiles to be developed and tested based on these analyses; and preliminary biaxial braid compression garment modeling results.
\end{abstract}

\section{Nomenclature}

$\begin{array}{ll}\text { DEA } & =\text { dielectric elastomer actuator } \\ \text { EAP } & =\text { electroactive polymer } \\ \text { EMU } & =\text { extravehicular mobility unit } \\ \text { EVA } & =\text { extravehicular activity } \\ \text { MCP } & =\text { mechanical counter-pressure } \\ \text { NASA } & =\text { National Aeronautics and Space Agency } \\ \text { SMA } & =\text { shape memory alloy } \\ \text { SMP } & =\text { shape memory polymer }\end{array}$

\section{Introduction}

$\mathrm{B}$ eginning with the first spacewalk performed by Alexi Leonov in 1965, astronauts conducting extravehicular activity (EVA) have donned gas-pressurized space suits to stay alive in the harsh environment of space ${ }^{1}$. These suits function by creating an artificial gas environment that surrounds the user, mimicking the breathable atmosphere and complete-body counter-pressure found on the surface of the Earth. Considerable advances have been made in the field of space suit design since the 1960s, but the fundamental concept of a gas-pressurized enclosure has remained unchanged, and looks to be the modus operandi of NASA and its subcontractor community for the foreseeable future ${ }^{2}$.

While the primary objective of the space suit is to keep the astronaut safe, it is also critical that the suit does not prevent the astronaut from physically completing mission tasks. After safety, flexibility and mobility are perhaps the most important design considerations for suit engineers ${ }^{2}$. However, traditional gas-pressurized suits are notoriously inflexible. Gas pressurization causes stiffening of the soft suit materials, and changes in internal volume and

\footnotetext{
${ }^{1}$ Ph.D. Student and NASA Space Technology Research Fellow, Department of Aeronautics and Astronautics, Room 37-219, 77 Massachusetts Avenue, Cambridge, MA 02139. AIAA student member.

${ }^{2}$ Undergraduate Student, Department of Aeronautics and Astronautics, Room 37-219, 77 Massachusetts Avenue, Cambridge, MA 02139. AIAA student member.

3 Assistant Professor, Department of Media Arts and Sciences, Room E14-548L, 77 Massachusetts Avenue, Cambridge, MA 02139.

${ }^{4}$ Professor, Department of Aeronautics and Astronautics and Engineering Systems, Room 33-307, 77 Massachusetts Avenue, Cambridge, MA 02139. AIAA member.
} 
pressure caused by deformation of the suit joints during movement force the astronaut to expend energy every time he or she bends the suit away from its equilibrium position ${ }^{3-4}$.

Mechanical counter-pressure (MCP) space suits have the potential to greatly improve the mobility of astronauts as they conduct planetary exploration activities. MCP suits, which differ from traditional gas-pressurized space suits by applying surface pressure directly to the wearer using tight-fitting materials rather than pressurized gas, represent a fundamental change in space suit design. By altering the pressurization mechanism, MCP suits act as a conformal, wetsuit-like mobile garment rather than an inflexible balloon, vastly reducing the mass of the suit while simultaneously mitigating the risk of catastrophic failures due to puncture or depressurization ${ }^{5}$. As a result, MCP suits represent a promising breakthrough technology for future exploration missions.

While MCP suits were first proposed over 40 years ago, challenges still exist to realize flight implementation ${ }^{6-8}$. The underlying technologies required to provide uniform compression at sufficient pressures for space exploration have not yet been perfected, and the challenge of donning and doffing such a suit remains unsolved ${ }^{8}$. The most promising solution to both of these problems lies in active materials technology. Active materials, such as shape memory alloys (SMAs) and electroactive polymers (EAPs), possess the ability to change shape when stimulated, and have been considered for application in everything from robotic actuators to self-expanding stents ${ }^{9-14}$. Integrating these technologies into a wearable garment could lead to smart fabrics capable of altering their compression characteristics upon command. Such a technology would bring MCP suits much closer to operational viability, and could be leveraged for other purposes where compression garments are found to be useful, including physical therapy, competitive sports, and battlefield medicine ${ }^{15-17}$.

\section{Mechanical Counter-Pressure History and Design Requirements}

The concept of MCP space suits was first proposed and explored in the 1960s and 1970s by Webb and Annis (the Space Activity Suit, see Fig. 1a), but the concept was tabled due to limitations in available materials, user discomfort, funding, and donning and doffing challenges ${ }^{6}$. More recent research efforts to advance MCP suit design have been conducted at multiple universities, including at the University of San Diego and in the Man Vehicle Laboratory (MVL) at MIT ${ }^{5,7-8,18-26}$. The MIT BioSuit ${ }^{\mathrm{TM}}$ system (see Fig. 1b-c), designed by Prof. Dava Newman, represents an innovative, modern approach to MCP suit design. The underlying concepts of this suit have been demonstrated through sub-component static testing, and full-suit mockups have been developed and produced to illustrate advanced restraint patterning ${ }^{5,20,24}$.

The driving design requirement of an MCP suit is that it must provide sufficient counter pressure to keep the user alive. By setting a target counter pressure requirement equal to that of current gas-pressurized space suit designs, performance requirements can be developed to prioritize the choice of constituent materials. Additional design
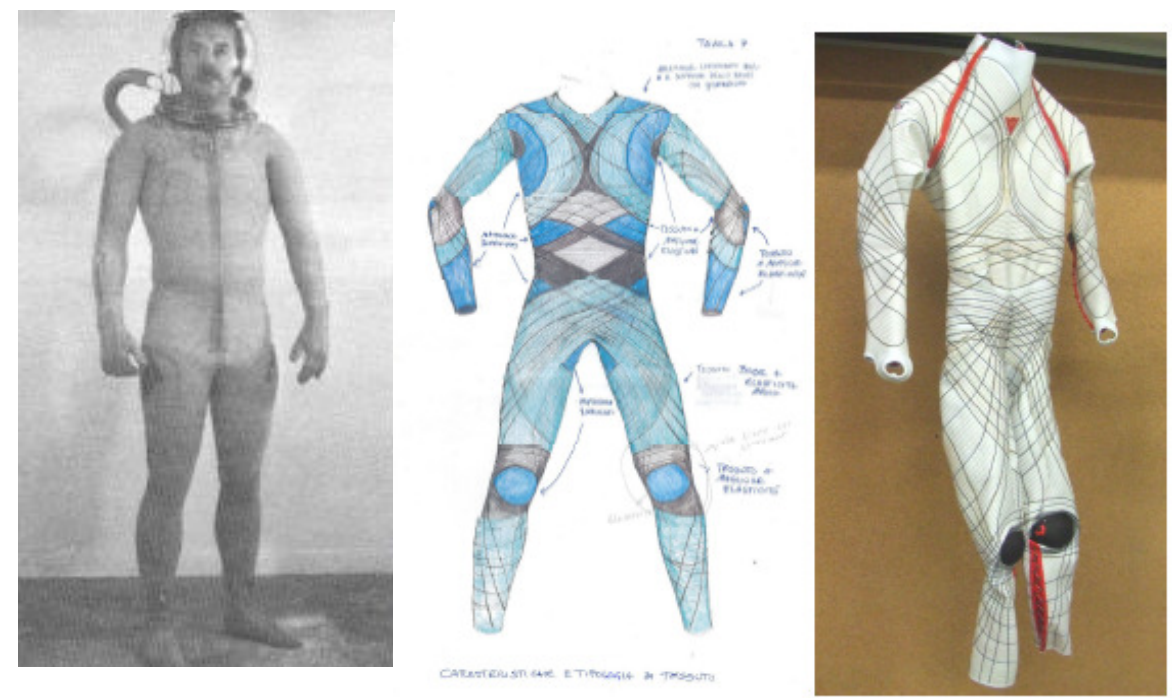

Figures 1a-c. MCP suit designs - Space Activity Suit, and BioSuit ${ }^{\mathrm{TM}}$ artist conception and mockup ${ }^{28-29}$ goals to maximize suit mobility are also considered. The following are considered baseline MCP requirements: target pressure production is $29.6 \mathrm{kPa}$ (4.3 psi), matching the internal gas-pressurization of the current Extravehicular Mobility Unity (EMU) space suit $^{27}$; and desired maximum material thickness is initially set to $5 \mathrm{~mm}$ to maintain compliance with the "second-skin" design goal.

Assuming a thin-walled cylindrical structure, these requirements set a minimum internal hoop stress of the pressure garment ${ }^{8}$, determined by Eq. (1) and modeled in Fig. 2: 


$$
\sigma_{\theta}=\frac{\operatorname{Pr}}{b}=\frac{F}{b l}=\frac{T}{b}
$$

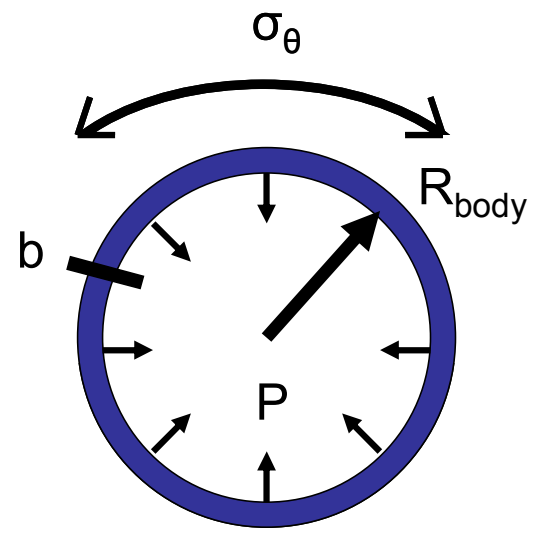

\section{Figure 2. Model of an MCP cross section assuming a thin-walled pressure vessel ${ }^{8}$}

In Eq. (1), $\sigma_{\theta}$ is hoop stress, $P$ is counter pressure, $r$ is local limb radius, $b$ is material thickness, $l$ is the axial length of the cylinder, $F$ is circumferential force acting on the area described by the thickness and length, and $T$ is the wall tension (defined as total circumferential force extended along the entire radial thickness). For the estimated largest limb radius (the upper thigh of a 95th percentile male, $10.7 \mathrm{~cm}$ ), a minimum active hoop stress of $0.633 \mathrm{MPa}$ at $5 \mathrm{~mm}$ thickness is required ${ }^{8,24,28}$. This corresponds to a wall tension of $31.65 \mathrm{~N} / \mathrm{cm}^{21}$. For limbs with smaller radii, smaller active stress values and wall tensions are required.

Knowing the minimum stress/tension characteristics necessary for MCP applications helps to constrain the list of candidate materials. An ideal material would be able to provide this level of stress/tension through a wide range of strains - this would help to both solve the existing donning/doffing challenges, and also help to accommodate minor changes in limb radius that naturally occur during movement (since a garment with such characteristics would have the ability to drastically change shape). When considering active materials for this application, several other material characteristics are important including: achievable active strain (to be maximized for ease of donning and doffing); strain rate; activation mechanism type and operating regime; suitability for use in a wearable garment; efficiency; stiffness; tensile strength; hysteresis; usable lifetime; and longitudinal stresses (to be minimized to enable maximum mobility).

\section{Analysis of Active Materials}

While widely studied for use as robotic actuators and other similar tasks because of their ability to function as artificial muscles ${ }^{9}$, active materials have only recently garnered attention for their potential to strategically augment or enhance wearable garments ${ }^{11,30}$. The interest in integrating active materials for smart fabrics is growing as the underlying material technologies mature, and avenues for new and innovative research in these areas are being continuously discovered ${ }^{31}$. The ability of active materials to produce a controllable compression garment has not been previously studied to the best of our knowledge, and this potential application serves as the primary motivation of this research effort. Several types of active materials exist, each with different capabilities, limitations, and characteristics. A broad survey of active materials was conducted, and focused on assessing the current state of an array of active material types with respect to the basic design requirements for an MCP garment ${ }^{9,13,32-35}$. For detailed descriptions of these material types, we recommend Madden et al. ${ }^{9}$ and Bar-Cohen ${ }^{34}$.

Based on the primary MCP requirements of maximum active strain given a strict minimum acceptable stress, each material type was graded in one of three ways: accepted for further study (indicating that it meets both design requirements); considered for further study (indicating that it may meet design requirements pending further investigation); and not further considered (indicating that it failed in one or more critical design requirement). The results of this survey, and grades for each material type, are included in Table 1. The results of this survey are also presented in Fig. 3, with materials presented in terms of their reported maximum stress and strain ranges (decreasing performance from top to bottom assuming acceptable minimum stress value). Optimum materials (denoted by an asterisk) provide maximum active strain while accommodating at least the minimum stresses described in section II. 
Table 1. Summary and assessment of active material categories based on maximum stress and achievable activation strain ${ }^{9,13,32-36}$

\begin{tabular}{cc|c|c|c} 
Material & $\begin{array}{c}\text { Maximum } \\
\text { Stress (MPa) }\end{array}$ & $\begin{array}{c}\text { Maximum } \\
\text { Strain (\%) }\end{array}$ & $\begin{array}{c}\text { Actuation } \\
\text { Mechanism }\end{array}$ & Assessment \\
\hline Dielectric Elastomer & $0.3-7.7$ & $120-380$ & $\begin{array}{c}\text { Applied Voltage } \\
(>1 \mathrm{kV})\end{array}$ & $\begin{array}{c}\text { Accepted for } \\
\text { further study }\end{array}$ \\
\hline Shape Memory Polymer & 4 & 100 & Multiple & $\begin{array}{c}\text { Accepted for } \\
\text { further study }\end{array}$ \\
\hline Ferroelectric Polymer & $20-45$ & $3.5-7$ & $\begin{array}{c}\text { Applied Voltage } \\
(>1 \text { kV) }\end{array}$ & $\begin{array}{c}\text { Considered for } \\
\text { further study }\end{array}$ \\
\hline Ionic Polymer Metal Composite & $0.23-15$ & $0.5-3.3$ & $\begin{array}{c}\text { Applied Voltage } \\
(1-7 \text { V) }\end{array}$ & $\begin{array}{c}\text { Considered for } \\
\text { further study }\end{array}$ \\
\hline Shape Memory Alloy & $>200$ & $4-8$ & $\begin{array}{c}\text { Thermal Stimulus } \\
\text { Considered for } \\
\text { further study }\end{array}$ \\
\hline Carbon Nanotubes & $>20000$ & $0.2-1$ & $\begin{array}{c}\text { Applied Voltage } \\
(1-30 ~ V)\end{array}$ & $\begin{array}{c}\text { Not further } \\
\text { considered }\end{array}$ \\
\hline Liquid Crystal Elastomer & $0.01-0.45$ & $19-45$ & $\begin{array}{c}\text { Electrostatic } \\
\text { Stimulus }\end{array}$ & $\begin{array}{c}\text { Not further } \\
\text { considered }\end{array}$ \\
\hline Magnetostrictives & $7.8-110$ & $0.2-1.7$ & $\begin{array}{c}\text { Applied Voltage } \\
(1500 \text { V) }\end{array}$ & $\begin{array}{c}\text { Not further } \\
\text { considered }\end{array}$ \\
\hline
\end{tabular}

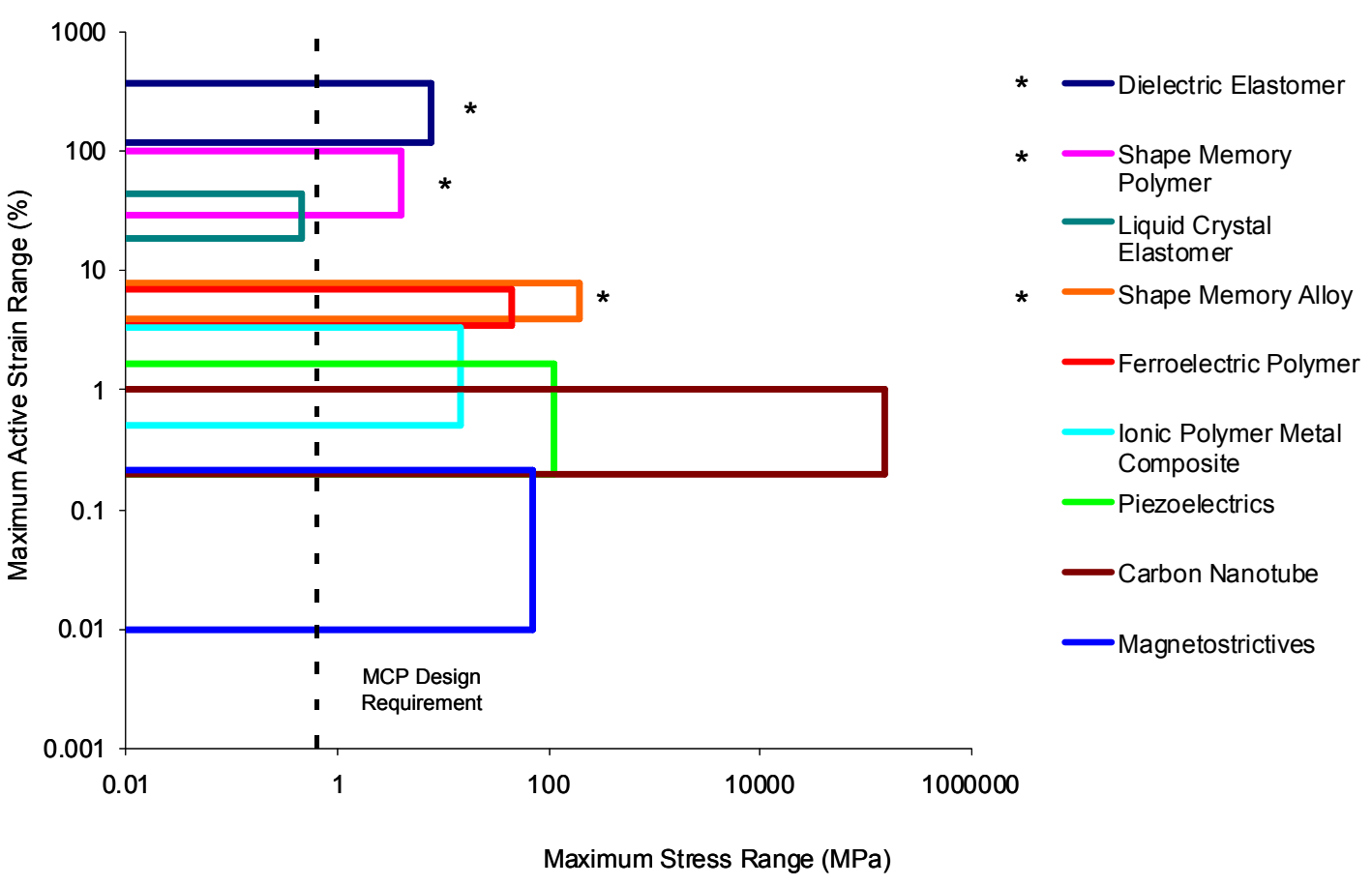

Figure 3. Relative stress/strain performance of several active material categories (logarithmic scale) Selected active materials for MCP textile design are identified by asterisk. 
Four material types (piezoelectrics, liquid crystal elastomers, magnetostrictives, and carbon nanotubes) were eliminated due to significant limitations in their performance (i.e., they failed to meet minimum stress levels, or they produce strains too small to be useful for this application). Dielectric elastomer actuators (DEAs) and shape memory polymers (SMPs) were accepted for further study. Shape memory alloys (SMAs), ferroelectric polymers, and ionic polymer metal composites were examined for further study; ultimately ferroelectric polymers and ionic polymer metal composites were rejected due to minimal active strain capability given the required voltages and reliance on embedded fluids, respectively. The three materials accepted for this study (SMA, SMP, DEA) correspond to the three top-most active strain materials that met minimum stress requirements as seen in Fig. 3. Detailed descriptions of each selected material follow.

Dielectric Elastomer Actuators (DEAs): DEAs are comprised of an elastomer film coated on each side with conductive layers. When exposed to an electric field, the conductive layers experience electrostatic attraction, producing Maxwell pressure, which in turn induces compressive strains on the elastomer film leading to actuation $^{9,37}$. This concept is illustrated in Fig. 4.

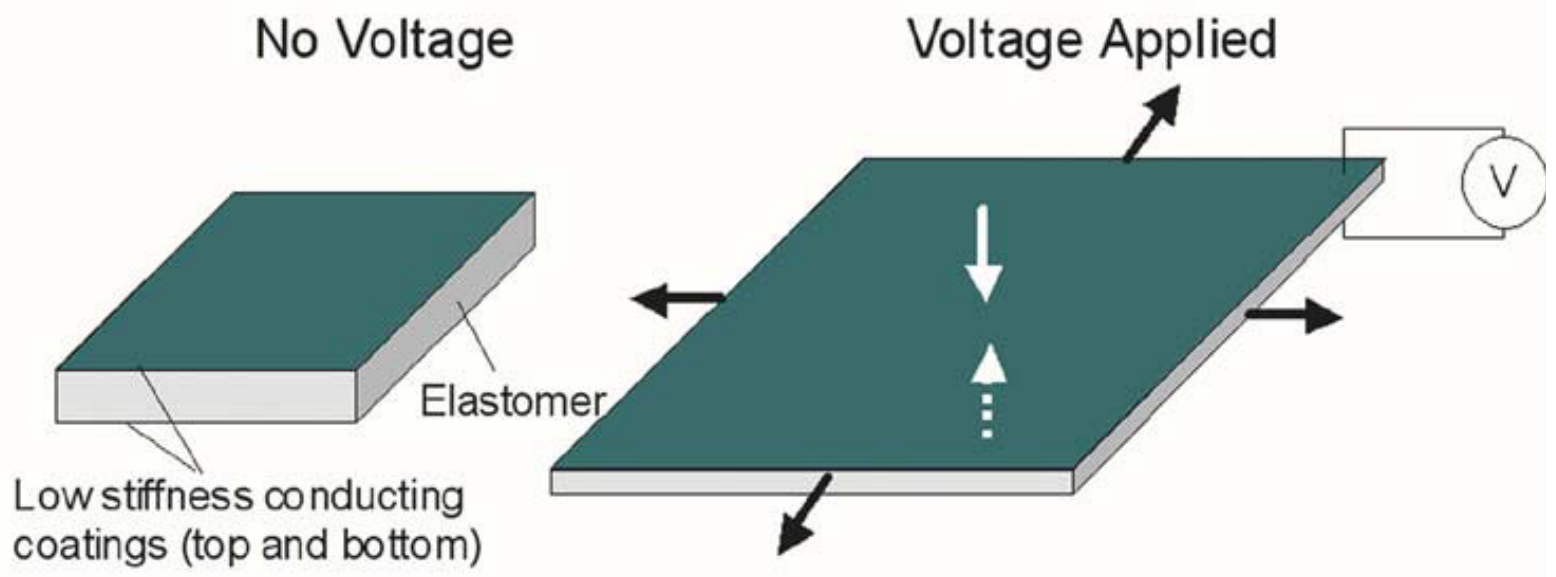

Figure 4. Dielectric elastomer schematic ${ }^{9}$

Maxwell pressure, and thus the induced and strain on the elastomer, are governed by the following equation:

$$
p=\varepsilon \varepsilon_{0} E^{2}=\varepsilon \varepsilon_{0}\left(\frac{V}{t}\right)^{2}
$$

where $P$ is Maxwell pressure, $\varepsilon$ is the dielectric constant of the material, $\varepsilon_{0}$ is the permittivity of free space, $E$ is the imposed electric field, $V$ is the applied voltage, and $t$ is the polymer thickness. For a given strain, the required voltage and material thickness are directly proportional, meaning that required voltage can be minimized by minimizing the thickness of the elastomer film ${ }^{9,38-39}$. Contraction occurs in the plane that is normal to the conducting layers (i.e., the thickness). During the contraction phase, surface expansion occurs in the other two dimensions (which can be tailored depending on the actuator design).

DEAs have been shown to produce strains up to $120-380 \%$ by area ${ }^{9,37,40-41}$. For this reason, DEAs hold significant promise as artificial muscles or other robotic actuators ${ }^{40-42}$. Because DEAs produce expansion strains that are orders of magnitude larger than those of other active materials, as an individual element they could provide significant shape change ability to a compression garment when integrated circumferentially. Additional benefits of DEAs include the fact that they are easy to produce, are inexpensive, rely on simple electrostatic attraction for operation, have high efficiencies, and are shown to be repeatable (after softening) ${ }^{9,38}$. However, DEAs are not without limitation. They require kilovolt-level voltages, which in the application of a tight-fitting MCP garment may threaten user safety. The driving voltage may also prove to be power intensive if applied continuously, and the large induced strains can lead to durability issues of the elastomer as well as the activation electrodes'. Voltage can be minimized by decreasing the elastomer thickness and/or increasing the elastomer dielectric constant, however decreasing the thickness of the material used introduces other design challenges ${ }^{9,43}$.

Shape Memory Alloys (SMAs): SMAs are a category of metal alloys that demonstrate a shape-memory effect, which is the ability to return from a deformed state to a "remembered" state when exposed to a specific stimulus. 
This occurs as a result of a diffusionless solid-to-solid transformation between the alloy's austenitic and martensitic phases that is triggered by an external stimulus ${ }^{9}$. Stimuli can take several forms, including externally applied stress, heat, or magnetic fields, among others. Shape memory alloys also demonstrate superelasticity, which is the ability to fully recover its strain throughout a loading and unloading cycle, though hysteresis-based energy losses do occur ${ }^{44}$. The deformations that can be recovered through the shape memory effect are significant: Fig. 5 shows a time-lapse view of a SMA wire, deformed from its original configuration then exposed to heat, causing the sample to return to its original, un-deformed "memory" shape.

SMAs have been extensively studied, and their shape memory and elastic properties have proven useful in a wide variety of applications, ranging from robotic actuators and prostheses to bridge restraints, valves, deformable glasses frames, biomedical devices, and even wearable garments ${ }^{30,45-49}$. The memory effect has been demonstrated in several alloy types, though the most common and commercially available alloy produced is NiTi (approximately $55 \%$ Nickel and $45 \%$ Titanium), under brands such as Nitinol ${ }^{\circledR}$ and Flexinol ${ }^{\circledR}$. Such alloys can be purchased in wire, tube, strip, or sheet form in varying thicknesses and diameters, and their deformation recovery capabilities scale with element size.

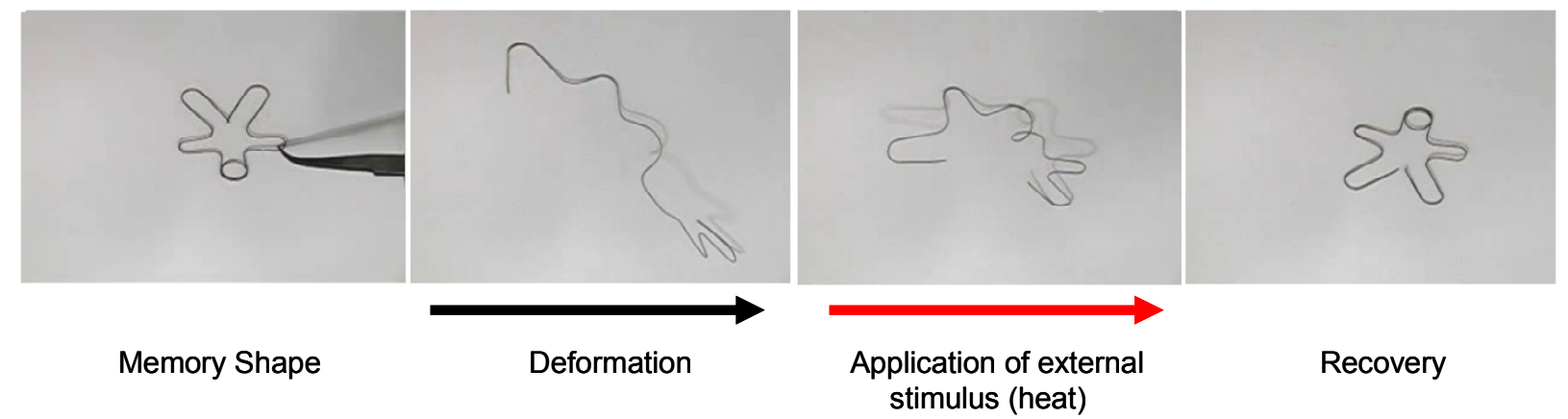

Figure 5. Time lapse view of a SMA, deformed from its original shape, returning to its shape due to an external thermal stimulus ${ }^{50}$

With proper design and manufacturing, shape memory alloys can produce large forces, recover from large deformations, and have been integrated into textiles in both fibrous (fine weave) and wire (coarse matrix) configurations. Moreover, SMAs are widely available, and are relatively inexpensive. These features make them attractive for use in a controllable compression garment. A limitation of SMAs, however, is the small magnitude of recoverable strain. State of the art SMAs demonstrate strains that peak in the single-digit percentage range ${ }^{9,51}$. This poses challenges for applications that require large stroke lengths. This limitation may prove critical when designing a controllable compression garment, as compression requires constriction of the surrounding garment, which is most easily achieved through length-wise (i.e., circumferential) constriction of the garment's individual active elements. It is infeasible to expect that a SMA-based compression garment would be able to produce the desired counterpressure $(30 \mathrm{kPa})$ for a MCP suit by virtue of the strain of the SMAs alone. This limitation does not preclude the use of SMAs in a compression garment; it does, however, require designs that exploit other useful features of SMAs to produce compression (namely, their superelasticity and large deformation recovery abilities).

Shape Memory Polymers (SMPS): SMPs can be thought of as analogs to SMAs - polymers with shape memory characteristics that demonstrate deformation recovery capabilities. While SMAs get their memory effect from diffusion-less phase changes within the metal alloy, SMP memory effects are derived from low-temperature glass or melting transitions (whereby internalized stresses are released), and the polymers themselves are generally physically or chemically cross-linked. SMPs are generally highly conductive materials, and their shape memory effect is generally irreversible (in order to return to its remembered state, the polymer must be externally deformed) $)^{9,11,13,52}$.

Hundreds of polymers have been identified that demonstrate shape memory effects ${ }^{13}$. As is the case with SMAs, SMPs have been studied for use in countless applications where actuation is desired, as they are easily configurable to accommodate different geometries and critical activation temperatures. Applications range from morphing biomedical implants, to integrated temperature sensors, deployable hinges, and transformable textiles ${ }^{11,53-55}$. SMPs mimic SMAs in most all relevant categories: performance (high recoverable deformation under desired stress conditions that scales with element size); availability (commercially available); versatility (wide variety of types and operating regimes); as well as limitations (low force production and smaller average active strains than DEAs). 


\section{Textile Architecture Analysis}

Critical to this research effort, in addition to active materials selection, is the selection of the garment architecture in which the active material(s) will be embedded. This requires us to consider textile structures for garments with one or more active elements, each with specific capabilities and limitations. SMA and SMP materials offer large recoverable deformation whereas DEA materials offer large recoverable strains. This difference may lead to a divergence in optimal textile design depending on the selected material. Textile fabrics can generally be categorized into three classes: woven fabrics, knitted fabrics, and non-woven fabrics ${ }^{56-57}$. Each of these classes has unique properties, advantages, and limitations:

- Woven fabrics use two independent sets of yarn aligned perpendicularly to one another (referred to as the warp, the lengthwise yarn, and the weft or fill, the crosswise yarn), with the weft fibers inserted over and under successive warp lines in a pattern dependent on the desired weave type (see Fig. 6a). Woven fabrics are the most widely produced type of fabric, and contain two bias axes, which lie at 45 degree angles to the warp and weft axes. Bias axes are more elastic than the warp and weft axes, but have less strength ${ }^{56-57}$.

- Knitted fabrics, unlike woven fabrics, use a single set of yarn that is looped through itself, and the yarn is oriented in the same direction through the entire garment (see Fig. 6b). Knitted fabrics can take either weft- or warp-knitted architectures, depending on whether the yarn moves along the length or the width of the fabric ${ }^{56-57}$.

- Non-woven fabrics include any type of fabric not woven or knitted, and consist of interconnected fibers bonded by mechanical, chemical, thermal, or other means (see Fig. 6c). The most common example of non-woven fabrics is felt ${ }^{56-57}$.

Beyond these three traditional textile fabric classes, other complex structures and architectures exist that may be relevant to active material compression garment design.

- Oblique Interlaced, or Braided, textiles are composed of individual elements oriented at oblique angles to the edge of the fabric that pass under and over intersecting elements (also at oblique angles) with a common directional trend ${ }^{58}$. Several different braiding structures (diamond, Hercules), axial configurations (biaxial, triaxial), fiber diameters, porosities, and interlacing angles are possible. A biaxial braid structure is demonstrated in Fig. 7a-b. Braids are commonly used in everything from children's toys (like the finger trap) to advanced carbon fiber composites ${ }^{59}$. Because of its unique textile architecture, the fiber elements in a braided cylinder are free to rotate angularly with respect to one another, enabling the cylinder to increase in length when loaded (causing a simultaneous decrease in radius) ${ }^{58}$. For this reason, braided tubes have been utilized in many actuation and morphing engineering structures, including pneumatic artificial muscles (McKibben actuators), expandable tubing sheaths, and in-vitro stents, and hold particular promise for compression garment design ${ }^{12,60-62}$.

- Looping, Twisting, and Interlinking textiles are structures composed of individual fibers, yarns, or fabric elements that are twisted and/or looped around adjacent elements in an alternating fashion ${ }^{58}$. Several variants and combinations exist (simple linking, link and twisting, spiral interlinking, looping with interlocked stitching, etc.), three of which are shown in Fig. 8a-c. These structures differ from braids significantly, as individual elements are effectively fastened to adjacent elements as a result of the linking/twisting/knotting structure, and each element changes directionality after each interaction (whereas braided elements maintain constant directionality). Looped, twisted, and interlocked structures are ubiquitous in everyday life, as they are used in everything from chain link fences to simple netting.
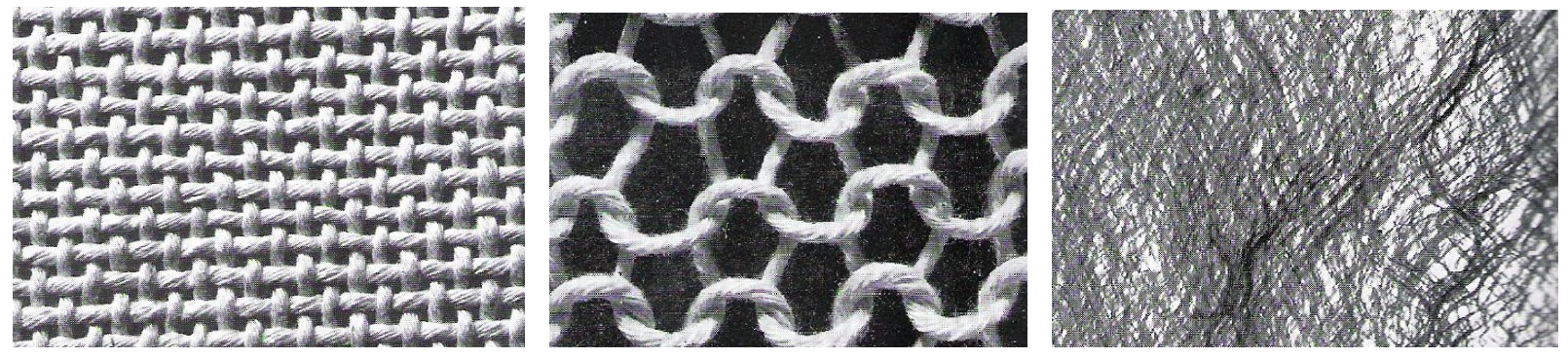

Figures 6a-c. Woven (left), knitted (center), and non-woven fabric architectures (right) ${ }^{58}$ 

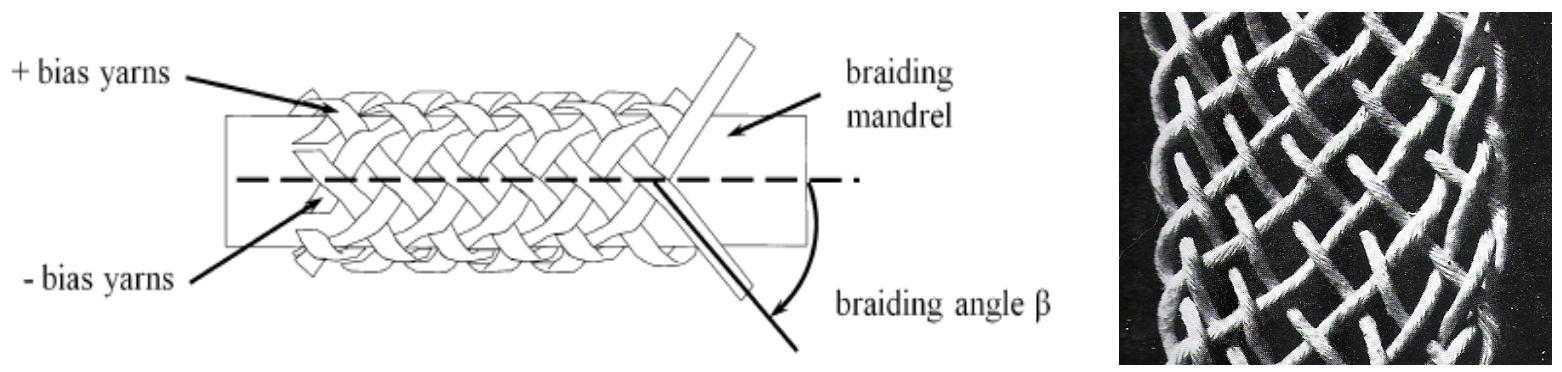

Figures 7a-b. Biaxial braid (interlaced) architecture schematic (left) and example (right) ${ }^{58-59}$
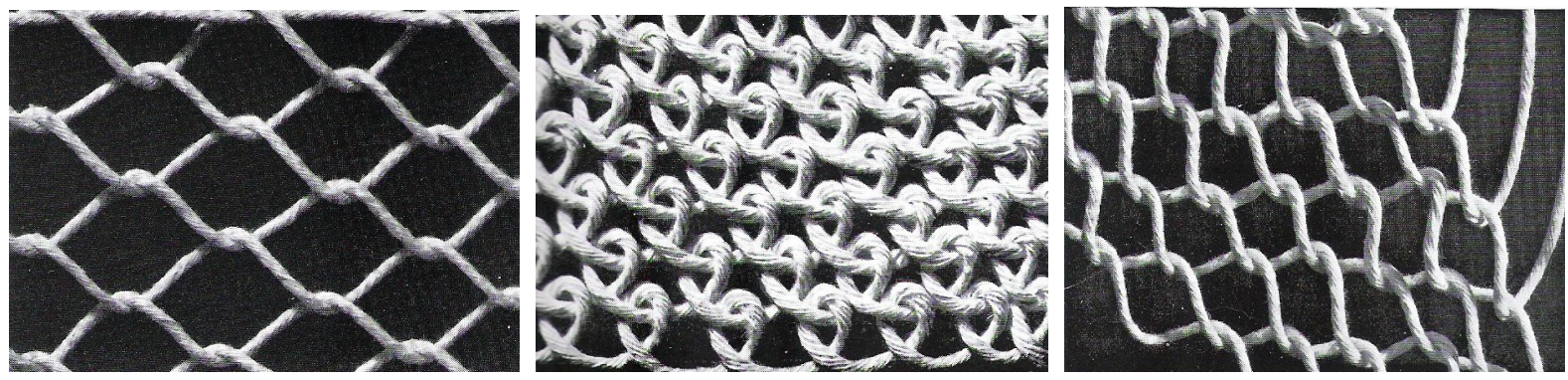

Figures 8a-c. Simple linking (left), looping with interlocked stitching (center), and spiral interlinking (right) textile architectures ${ }^{58}$

SMAs, SMPs and DEAs each have different operating mechanisms, strengths, and limitations that may impact their viability in a given textile architecture. DEAs produce large strains and are nominally produced in ribbon or sheet-type architectures, and are dependent upon planar electric stimulation to produce actuation. Their ability to recover large strains make DEAs attractive for compression garments with wide circumferential elements (such as a coarse weave or non-woven sheath), but are vulnerable to electrical isolation and interaction effects if integrated into a dense, multi-element configuration (eliminating traditional textile architectures from consideration). SMAs and SMPs can be produced in fibrous/wire form, and demonstrate large recoverable deformation capabilities under many different actuation stimuli that scale with fiber diameter. SMAs and SMPs do not generally produce large elementwise recoverable strains. These types of materials thus require garment designs that achieve compression through controllable deformation and interaction effects (such as braids or linked/twisted textiles), and benefit from coarse (rather than fine) fiber structure as the active response scales with fiber diameter.

As a result, three limiting factors exist that set the textile design space for active material compression garments: nature of the active material (controllable deformation vs. controllable strain); form of the active material element (fiber vs. sheet, coarse vs. fine); and textile architecture (circumferential vs. biased elements, weave/knit vs. nonweave, interlaced vs. interlinking). Given the material types and fabric classes/structures available, a matrix of possible material/fabric architectures was developed to constrain the design space for an active material compression garment, and each material-textile architecture combination was graded (A, B, C) depending on their estimated performance as a controllable compression garment, resulting in several downselected architectures for development. This analysis, including brief justification for each assessment, is included as Table 2. Three materialtextile architectures were identified as best suited for controllable compression design: DEA non-woven sheath; SMA/SMP coarse braid; and SMA/SMP coarse looping/interlinking mesh. Other options were ranked below these for several reasons, including construction complexity (i.e., DEA braid); potential for stimulus (thermal, electrical) interference (i.e., DEA weave and braid); lack of clear mechanism to produce compression (i.e., SMA/SMP weave and knit); and inefficient material sizing (fine SMA/SMP fiber architectures).

Additional design considerations (garments that combine multiple active materials, garments that include both passive and active elements, etc.) will also be explored as part of this research effort, but are not included in this trade space. 
Table 2. Material-textile architecture trades space analysis and downselect

\begin{tabular}{|c|c|c|c|c|c|}
\hline Active Material Type & Nature of Active Material & Active Material Form & $\begin{array}{l}\text { Possible Textile } \\
\text { Architecture }\end{array}$ & Grade & Justification \\
\hline \multirow{3}{*}{ Dielectric Elastomer } & \multirow{3}{*}{$\begin{array}{l}\text { Controllable individual } \\
\text { element strain }\end{array}$} & \multirow{2}{*}{ Ribbon or Band } & $\begin{array}{l}\text { Coarse weave } \\
\text { (with active ribbons } \\
\text { along the weft) }\end{array}$ & B & $\begin{array}{c}\text { Directly utilizes active strain capabilities, but } \\
\text { introduces interaction effects and electrical isolation } \\
\text { issues }\end{array}$ \\
\hline & & & $\begin{array}{l}\text { Coarse braid } \\
\text { (with active ribbons } \\
\text { along each bias yarn) }\end{array}$ & C & $\begin{array}{c}\text { Complex construction, inefficient compression } \\
\text { mechanism, introduces interaction effects and } \\
\text { electrical isolation issues }\end{array}$ \\
\hline & & $\begin{array}{l}\text { Ribbon, Band, or } \\
\text { Continuous Sheet }\end{array}$ & $\begin{array}{c}\text { Non-woven sheath } \\
\text { (comprised of continous } \\
\text { active material) }\end{array}$ & A & $\begin{array}{l}\text { Simplicity in pressure production mechanism, } \\
\text { directly utilizes active strain capabilities }\end{array}$ \\
\hline \multirow{8}{*}{$\begin{array}{l}\text { Shape Memory Alloy } \\
\text { Shape Memory Polymer }\end{array}$} & \multirow{8}{*}{$\begin{array}{l}\text { Controllable individual } \\
\text { element deformation }\end{array}$} & \multirow{4}{*}{$\begin{array}{l}\text { Small Diameter Fiber } \\
\text { (spun into yarn) }\end{array}$} & $\begin{array}{l}\text { Fine weave } \\
\text { (with active yarn } \\
\text { along the weft) }\end{array}$ & C & $\begin{array}{l}\text { Unclear how to utilize deformation recovery to } \\
\text { produce compression }\end{array}$ \\
\hline & & & $\begin{array}{c}\text { Fine knit } \\
\text { (with active yarn } \\
\text { along the warp or weft) }\end{array}$ & C & $\begin{array}{l}\text { Unclear how to utilize deformation recovery to } \\
\text { produce compression }\end{array}$ \\
\hline & & & $\begin{array}{c}\text { Fine braid } \\
\text { (with active fiber } \\
\text { along each bias yarn) }\end{array}$ & B & $\begin{array}{l}\text { Material response scales with fiber thickness, } \\
\text { biasing designs towards large fibers }\end{array}$ \\
\hline & & & $\begin{array}{c}\text { Fine looping / } \\
\text { interlinking mesh } \\
\text { (comprised of active } \\
\text { yarns) }\end{array}$ & B & $\begin{array}{l}\text { Material response scales with fiber thickness, } \\
\text { biasing designs towards large fibers }\end{array}$ \\
\hline & & \multirow{4}{*}{$\begin{array}{l}\text { Large Diameter Fiber } \\
\quad \text { (wire or cable) }\end{array}$} & $\begin{array}{l}\text { Coarse weave } \\
\text { (with active wire } \\
\text { along the weft) }\end{array}$ & C & $\begin{array}{l}\text { Unclear how to utilize deformation recovery to } \\
\text { produce compression }\end{array}$ \\
\hline & & & $\begin{array}{c}\text { Coarse knit } \\
\text { (with active wire } \\
\text { along the warp or weft) }\end{array}$ & C & $\begin{array}{l}\text { Unclear how to utilize deformation recovery to } \\
\text { produce compression }\end{array}$ \\
\hline & & & $\begin{array}{l}\text { Coarse braid } \\
\text { (with active fiber } \\
\text { along each bias yarn) }\end{array}$ & A & $\begin{array}{l}\text { Textile architecture exploits material strengths } \\
\text { (recoverable deformation) }\end{array}$ \\
\hline & & & $\begin{array}{c}\text { Coarse looping / } \\
\text { interlinking mesh } \\
\text { (comprised of active } \\
\text { yarns) }\end{array}$ & A & $\begin{array}{l}\text { Textile architecture exploits material strengths } \\
\text { (recoverable deformation) }\end{array}$ \\
\hline
\end{tabular}

\section{Concept Active Material Compression Textiles}

Concepts for MCP garments include both active compression (i.e., activation leading to garment constriction), and passive compression with active expansion (i.e., activation leading to garment expansion for donning and doffing). These concepts will be fabricated and tested to assess their viability at producing controllable compression and their ability to facilitate subject donning and doffing. Detailed descriptions of these concepts follow, and illustrations of each textile concept are included as Fig. 9-11.

Continuous Non-Woven DEA Compression Sheath Concept: This concept uses a continuous, non-woven DEA cylindrical sheet that expands the compression garment upon activation to enable donning/doffing, then passively constricts around the wearer when deactivated. This concept, along with alternate architectures using either DEA bands wrapped helically with end constraints, or DEA swatches linked in series, are presented in Fig. 9a-b.
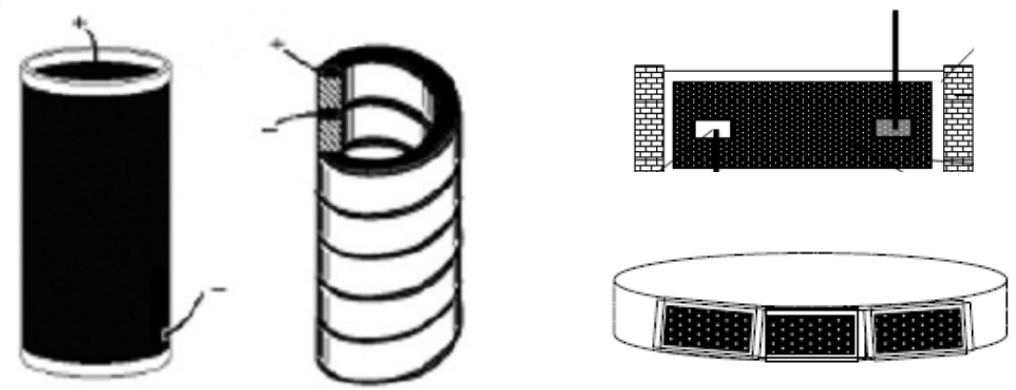

Figures 9a-b. DEA continuous compression sheath/helix concept (left) and serial expansion band concept (right) ${ }^{63-64}$

American Institute of Aeronautics and Astronautics 
Coarse-Fiber Biaxial Braid Concept (or coarse-fiber looping/interlinking mesh concept): This concept uses a cylindrical biaxially braided architecture to create radial compression/expansion through changes in cylinder length (similar to a Chinese finger trap or some stents). Upon activation, deformed SMA or SMP elements straighten, causing elongation of the garment and radial compression. An alternate architecture concept uses SMA/SMP elements in a looping/interlinking mesh cylinder, and activation causes straightening of the active elements drawing adjacent columns together. A coarse braided cylinder architecture is presented in Fig. 10.
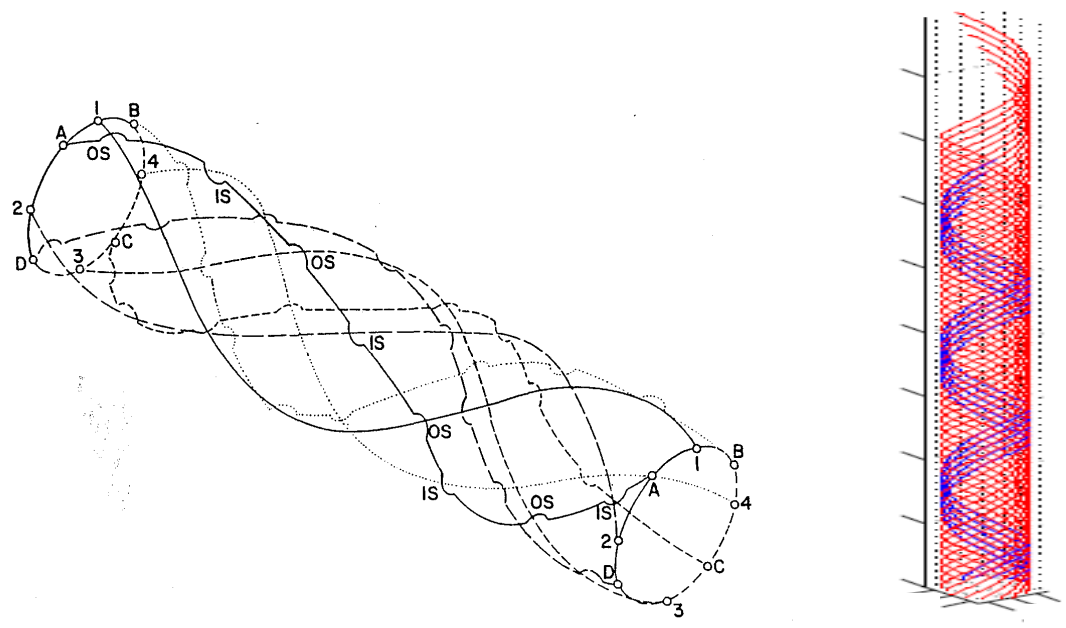

Figure 10. Biaxially braided cylindrical sheath concept with active elements ${ }^{65}$

Active Seam Concept: This concept integrates SMA or SMP bands longitudinally into a passive garment seam, enabling volume expansion when deactivated for donning and doffing. Activation leads to contraction of passive elements, pulling a seam together creating counter-pressure from the surrounding material ${ }^{20}$. This concept is shown in Fig. 11a-c.
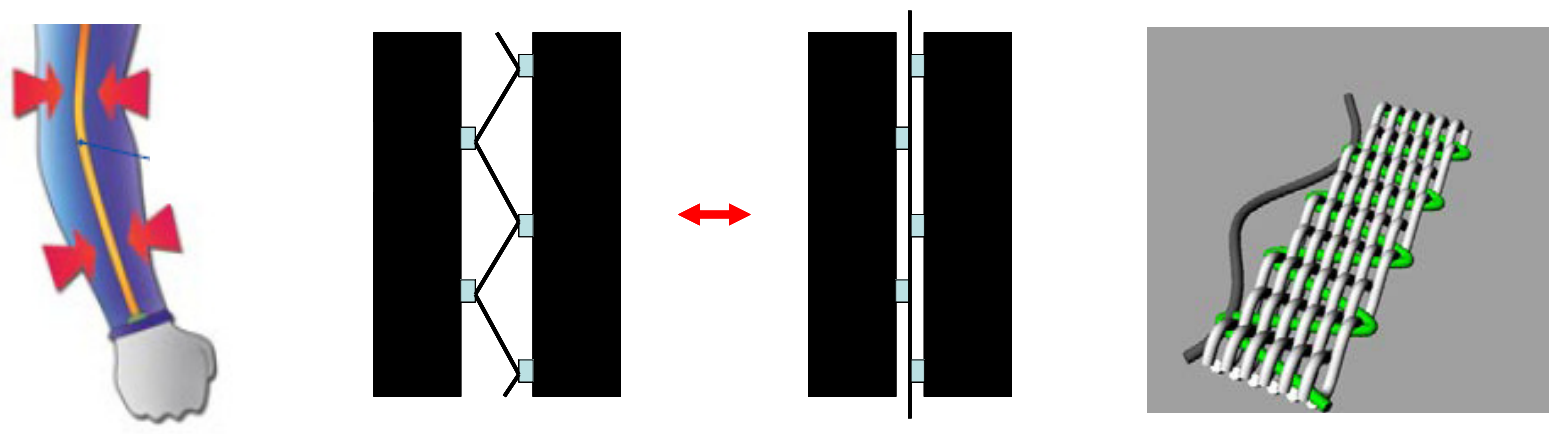

Figures 11a-c. Active seam concept combining passive and active elements to produce compression (illustration, schematic, and model, respectively) ${ }^{20,68}$

\section{Preliminary Textile Architecture Modeling}

In order to design compression garments based on complex textile structures like biaxial braids or looping/interlocking meshes, it is important to first model such geometries to understand how the elements in each textile will interact with one another, as these interactions will directly determine how the shape of the textile will change when activated and how it will respond mechanically when loaded. Because the field of active textiles is newly emerging, no standard modeling tools exist to characterize the behavior of morphing textiles. A mathematical model of biaxial braid geometries was derived as follows to predict the relationship between length and radius - a first step in understanding the compression behavior of a biaxial braid comprised of SMA/SMP elements. 
One strand of a biaxial braid follows a helical path as shown by Fig. 12a-b. A helix is described by three parametric equations as follows:

$$
\begin{aligned}
& x=r \cos (\theta) \\
& y=r \sin (\theta) \\
& z=c \theta
\end{aligned}
$$

where $r$ is the radius, $\theta$ is the swept angle in the xy-plane in radians, and $c$ is the height change per turn. The value $2 \pi \mathrm{c}$ is called the pitch or the vertical distance between loops. The arc length $s$ is:

$$
s=\theta \sqrt{r^{2}+c^{2}}
$$

A helix can also be unwrapped to reveal a triangle where the hypotenuse is the arc length, $s$. Figure 12c illustrates the relationship between height $(z)$, braid angle $(\varphi)$, radius $(r)$, and arc length $(s)$ :

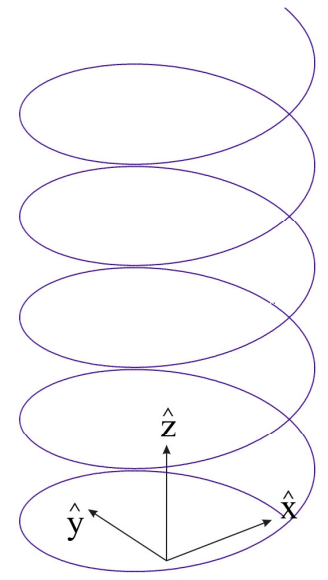

(a)

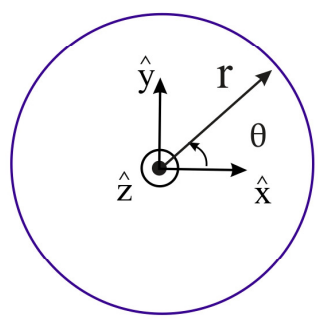

(b)

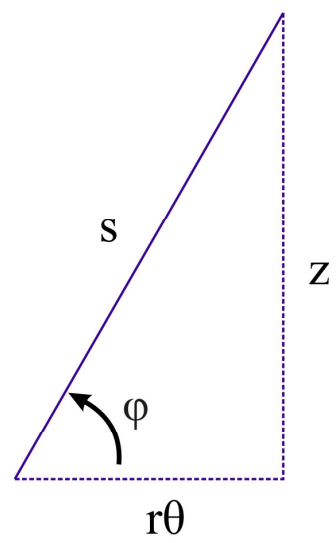

(c)

Figures 12a-c. Standard helix 3D view (left), top view (center), and unwound helix schematic (right)

The braid angle $\varphi$ is described by:

$$
\begin{aligned}
& \varphi=\arctan \left(\frac{z}{r \theta}\right) \\
& \varphi=\arctan \left(\frac{c}{r}\right)
\end{aligned}
$$

As the biaxial braid is stretched, $r$ decreases and $c$ increases. To describe this stretching behavior it is assumed that arc length is conserved and that the braid does not twist, which is described by:

$$
\begin{aligned}
& s_{0}=s_{1} \\
& r_{0}^{2}+c_{0}^{2}=r_{1}^{2}+c_{1}^{2}
\end{aligned}
$$

where subscripts represent the initial (subscript 0) and final (subscript 1) state of the braid. Contours of constant arc length are plotted in Fig. 13a where one contour represents a set of possible values for $r$ and $c$. Equation (10) can be expressed in terms of height $z$ by:

$$
z_{1}^{2}-z_{0}^{2}=\left(r_{0}^{2}-r_{1}^{2}\right) \theta^{2}
$$


Physical geometry for donning and doffing determines $z_{0}$ and $r_{0}$. The required pressure and fabric determines $r_{l}$ and the limb size will determine $z_{l}$. These can be used to solve for $\theta$ using Eq. (11). Figure 13b shows this equation applied to model the compressed and stretched state of a biaxial braid.
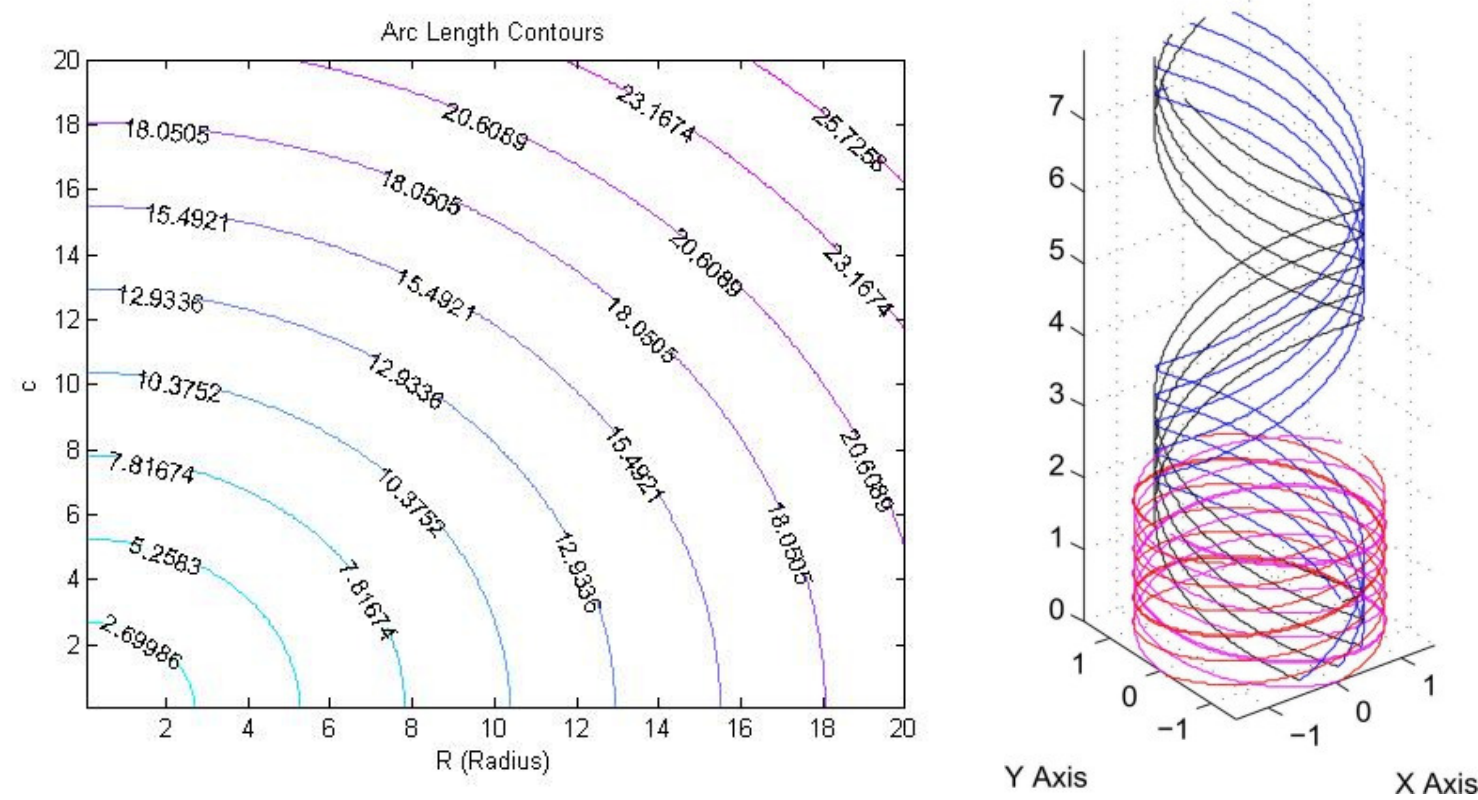

Figures 13a-b. Biaxial braid length vs. radius contour map for multiple arc lengths (left) and 3D representation of length/radius relationship (right)

An ideal finite helix can be stretched until it is a straight strand or compressed until it is a flat circle. However, actual strands have a finite width and biaxial braids are composed of a finite number of strands. This constrains the macro structure (minimum and maximum radius and height) of biaxial braids. Figure 14 shows a magnified view of packed strands when a biaxial braid is compressed to its maximum radius without straining the material.

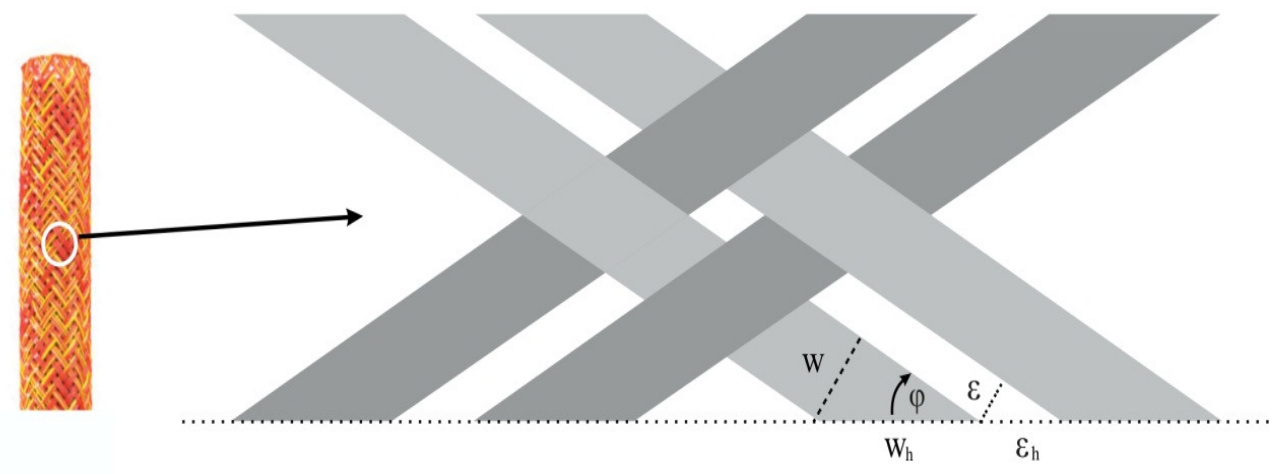

Figure 14. Biaxial braid unit cell at maximum compression

In Fig. 14, $w$ is the width of the fiber and $\varepsilon$ is the gap between fibers caused by the thickness of the strands being braided in the opposite orientation. The horizontal projections of $w$ and $\varepsilon$ are shown as $w_{h}$ and $\varepsilon_{h}$. Because the macrostructure of the braid is circular the following must be true:

$$
\begin{aligned}
& n\left(w_{h}+\varepsilon_{h}\right)=2 \pi r \\
& w_{h}=\frac{w}{\sin \varphi}
\end{aligned}
$$




$$
\begin{gathered}
\varepsilon_{h}=\frac{\varepsilon}{\sin \varphi} \\
n\left(\frac{w}{\sin \varphi}+\frac{\varepsilon}{\sin \varphi}\right)=2 \pi r \\
\varphi=\arctan \left(\frac{c}{r}\right) \quad \sin \varphi=\frac{c}{\sqrt{c^{2}+r^{2}}} \\
\frac{n s}{\theta c}(w+\varepsilon)=2 \pi r
\end{gathered}
$$

where $n$ is the number of strands. Note that $c$ is a function of $r$. When this function is solved for $r$ the minimum and maximum values of $r$ are obtained because there is no space between the braid fibers and the braid can no longer move. Solving these equations shows that there are two solutions for $r$ that are physically possible. For a solution $\mathrm{r}_{1}$ and $r_{2}$ the corresponding values of $c$ are $c_{2}=r_{1}$ and $c_{1}=r_{2}$, which is expected given the symmetry of the braid structure.

To assess this model, commercially available biaxial braids (TechFlex Flexo Clean Cut ${ }^{\mathrm{TM}} 0.375$ ", 0.75 ", 1.5 " nominal diameter) were purchased and their minimum/maximum length/radii characteristics were physically measured $^{66}$. Predicted vs. measured length/radius limits (extrema) for each braid are plotted in Fig. 15 (along with reference contours of constant arc length). The unique contour enclosed between the extrema represents the operating regime for a biaxial braid of the given arc length. This predictive capability could be used to design braided structures that meet specific morphing requirements for compression and donning/doffing (e.g., a lower leg braid that could both expand to accommodate the heel and contract to produce compression on the ankle).

Discrepancies between the predicted and actual values are likely caused by deviations from the assumption of an ideal helical structure for each braided element. Actual elements in a biaxial braid likely follow a helical quasi-sine wave rather than a simple helix due to the weaving effect stemming from element interactions.

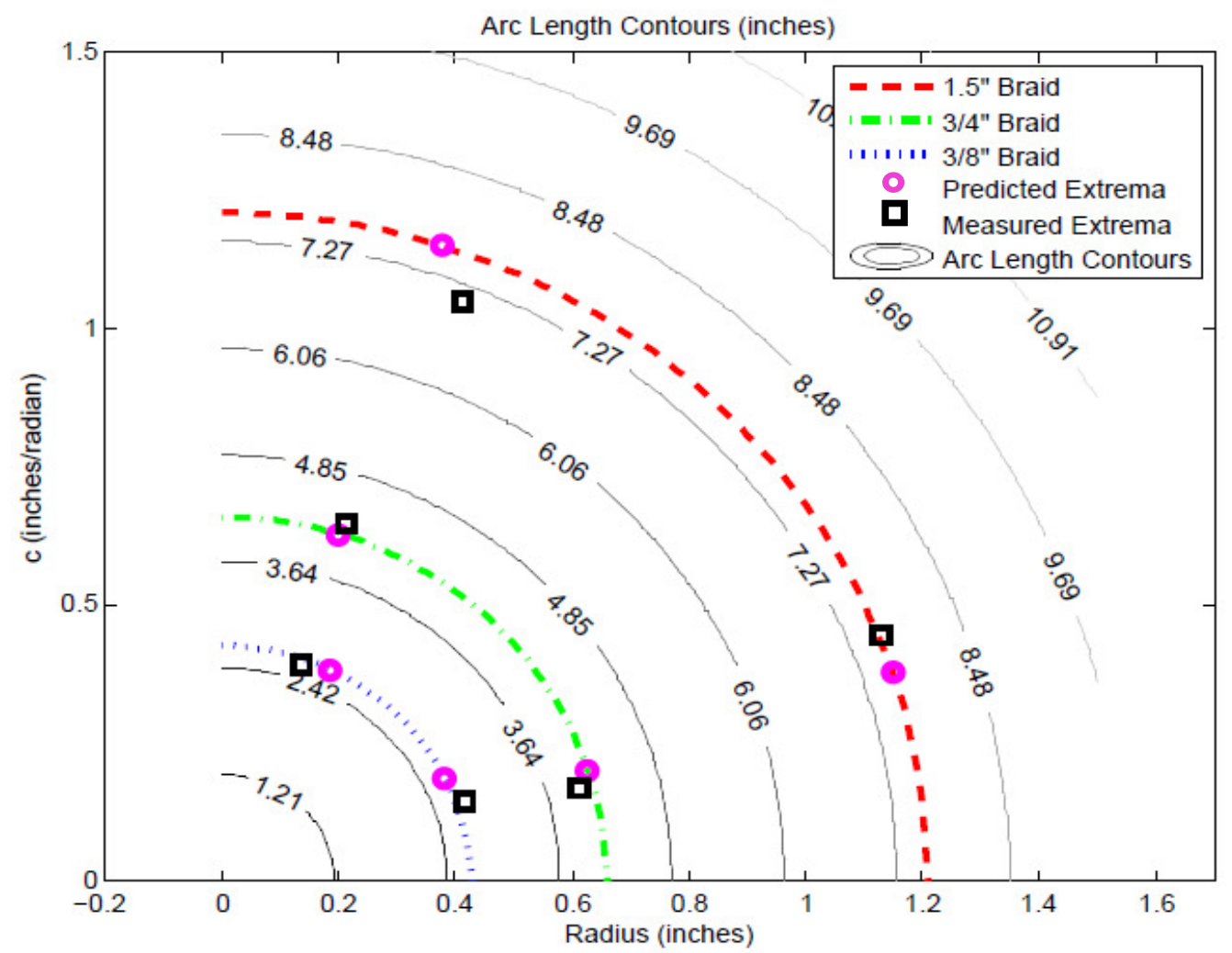

Figure 15. Theoretical vs. actual biaxial braid geometric constraints

13

American Institute of Aeronautics and Astronautics 
Assuming that a strand makes a sinusoidal path as it spirals, the sine portion of the curve has an amplitude and frequency determined by the thickness of the strands $b$ and the number of strands used $n$. The radius is then substituted by the effective radius (Eq. (18)). The phase shift (Eq. (19)) is used to represent the number of strands $n$ in one orientation used to create the overall braid. The mathematical parameterization becomes the following (Eqs. 20-22):

$$
\begin{aligned}
& r_{e f f}=a+b \sin \left[n \theta-\frac{\pi}{2}\right] \\
& \phi=(i-1) \frac{2 \pi}{n} \quad i=1,2,3 \ldots . n \\
& x=r_{e f f} \cos (\theta-\phi) \\
& y=r_{e f f} \sin (\theta-\phi) \\
& z=c \theta
\end{aligned}
$$

To represent the surface of each individual strand, open source textile weaving software TexGen was used ${ }^{67}$. Each peak and valley in the sine oscillation embedded in Eq. (18) is treated as a node in a TexGen model, which then interpolates between the nodes with a desired strand cross section to generate a surface. Figures $16 a-b$ show two examples of biaxial braids generated by TexGen using this method. TexGen files can reportedly be exported as geometry files that can be analyzed by Finite Element Analysis (FEA) software to determine the mechanical characteristics of a specific model, though this functionality has not yet been assessed in relation to this research effort.

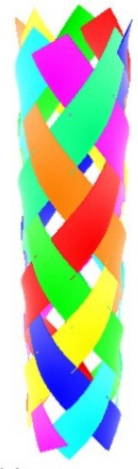

(a)

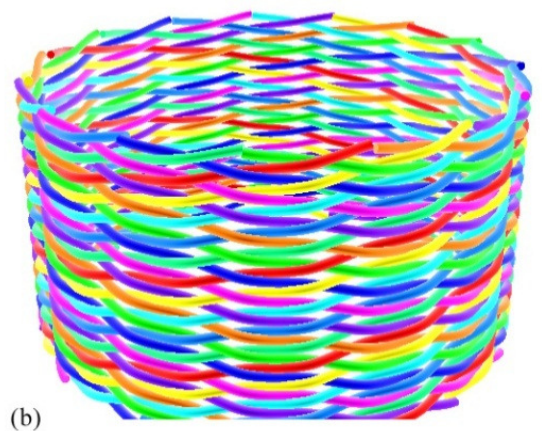

(b)

Figures 16a-b. Biaxial braid geometries generated using TexGen

To assess the feasibility of complex braided geometries more similar to those encountered in a conformal garment design, the biaxial braid model was refined to vary the effective radius a function of theta:

$$
r_{\text {eff }}=a(\theta)+b \sin \left[w \theta-\frac{\pi}{2}\right]
$$

The surface made by the walls of the biaxial braid is directly related to $a(\theta)$. This is possible because the shape is expressed by a parametric equation, and multiple phase shifted strands comprise the biaxial braid. The equations for each $\mathrm{x}$ - and $\mathrm{y}$-component are thus phase shifted, but the equation for each $\mathrm{z}$-component remains the same in each strand, which makes the shape radially symmetric. To demonstrate this, let $a(\theta)$ be the following fourth order equation:

$$
a(\theta)=-0.0164 \theta^{4}+0.267 \theta^{3}-1.32 \theta^{2}+2.15 \theta+2
$$


When the function described by Eq. (24) is revolved about the $\theta$ axis it forms the sidewalls of the biaxial braid in Fig. 17, demonstrating that complex braided geometries are physically possible and can be effectively modeled using TexGen. This provides the basis for modeling garments catered to specific body geometries that can be used in combination with active elements to create controllable compression technologies.
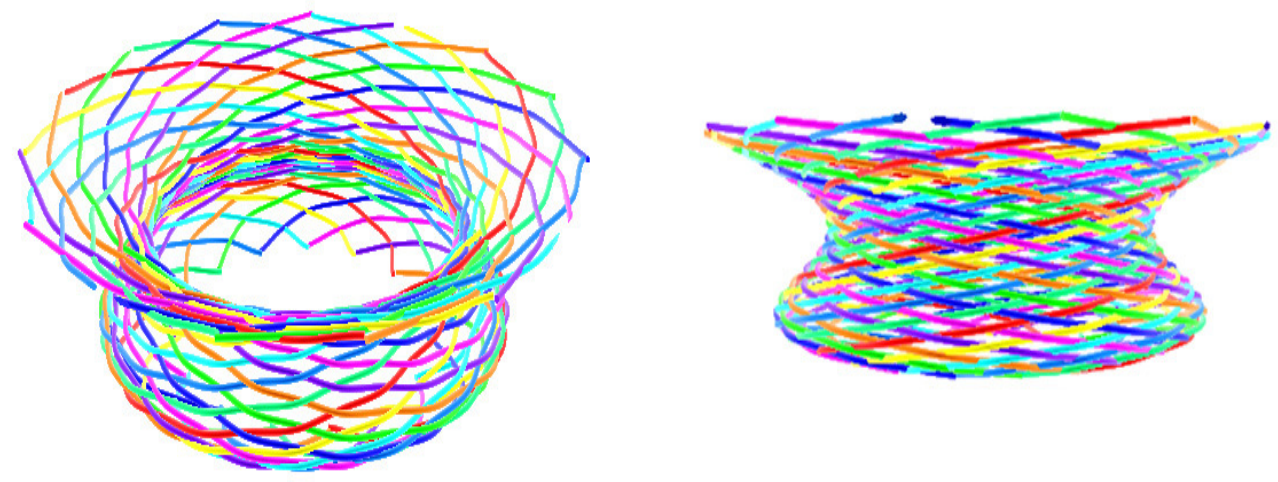

Figure 17. Biaxial braid architecture with varying radial profile produced using TexGen

The mathematical model presented does not yet incorporate material properties of the constituent elements, and is limited to describing the geometric behavior of braided cylinders of varying arc length, profile, element count, and element diameter. Future work includes enhancing this model to include material properties to better understand the mechanical behavior of each design.

\section{Conclusion}

This research aims to advance the state of the art of mechanical counter pressure space suit design by combining active materials technology with targeted textile design to produce controllable, conformal compression garments. We analyzed several active materials and identified DEAs, SMPs, and SMAs as candidate materials for MCP space suit inclusion. With these materials in mind, we surveyed existing textile architectures and identified non-woven sheaths, biaxial braids and interlinking meshes as architectures uniquely suited for active material integration to produce controllable compression. Finally, we modeled the physics of biaxial braids to characterize the morphing limits of a specified architecture, and we demonstrated the feasibility of modeling complex braided geometries for future conformal garment designs. Beginning with the analysis provided herein, we seek to refine our modeling capability, develop and test compression garment prototypes, and to provide a framework for future active material garment development pending advancements in material technology and textile manufacturing. The ultimate goal of this effort is to bring MCP suit technology closer to flight readiness, and to improve astronaut mobility for future planetary exploration.

\section{Acknowledgments}

This work is supported by a NASA OCT Space Technology Research Fellowship, NASA Grant NNX11AM62H "Development and Testing of Compression Technologies Using Advanced Materials for Mechanical CounterPressure Planetary Exploration Suits" as well as the MIT Portugal Program. The authors would like to thank their collaborators at NASA Johnson Space Center, NASA Langley Research Center, and MIT: Lindsay Aitchison, Amy Ross, Dr. Cheol Park, Prof. Chris Schuh, Prof. Jeff Hoffman, Dena Molnar, and Andrea Messidoro.

\section{References}

${ }^{1}$ Skoog, A., Abramov, I., Stoklitsky, A., and Doodnik, M. "The Soviet-Russian Space Suits: A Historical Overview of the 1960s"," Acta Astronautica Vol. 51, No. 1-9, 2002, pp. 113-31.

${ }^{2}$ Jacobs, S., and Tufts, D. "Follow-On Development of the Demonstrator Suit for Post-Shuttle Operations," 41st International Conference on Environmental Systems AIAA 2011-5030, 2011.

${ }^{3}$ Scheuring, R. "The Apollo Medical Operations Project: Recommendations to Improve Crew Health and Performance for Future Exploration Missions and Lunar Surface Operations". NASA/TM-2007-214755, 2007, pp. 6-9. 
${ }^{4}$ Holschuh, B., Waldie, J., Hoffman, J., and Newman, D. "Characterization of Structural, Volume and Pressure Components to Space Suit Joint Rigidity," International Conference on Environmental Systems 2009-01-2535, 2009.

${ }^{5}$ Newman, D., Hoffman, J., Bethke, K., Carr, C., Jordan, N., Sim, L., Campos, N., Conlee, C., Smith, B., Wilcox, J., Trotti, G., and Technologies, M. "Astronaut Bio-Suit System for Exploration Class Missions: NIAC Phase II Final Report." Massachusetts Institute of Technology, Cambridge, MA, 2005.

${ }^{6}$ Webb, P., and Annis, J. "The Principle of the Space Activity Suit." NASA CR-973, Washington, D.C., 1967.

${ }^{7}$ Ruckman, J., Hodgson, E., and Quinn, G. "Investigation of Joint Torque Characteristics for a Mechanical Counter - Pressure Spacesuit," International Conference on Environmental Systems. SAE, Savannah, GA, 2009.

${ }^{8}$ Anderson, A. "Addressing Design Challenges in Mechanical Counterpressure Spacesuit Design and Space-Inspired Informal Education Policy," Dept. Aeronautics and Astronautics. SM, Massachusetts Institute of Technology, Cambridge, MA, 2011.

${ }^{9}$ Madden, J., Vandesteeg, N., Anquetil, P., Madden, P., Takshi, A., Pytel, R., Lafontaine, S., Wieringa, P., and Hunter, I. "Artificial Muscle Technology: Physical Principles and Naval Prospects," IEEE J. Oceanic Engineering Vol. 29, No. 3, 2004.

${ }^{10}$ Stoeckel, Pelton, and Duerig. "Self-Expanding Nitinol Stents - Material and Design Considerations," 2003.

${ }^{11} \mathrm{Hu}$, J., and Chen, S. "A review of actively moving polymers in textile applications," Journal of Materials Chemistry Vol. 20, 2010, pp. 3346-3355.

${ }^{12}$ Schreiber, F., Schuster, P., Borinski, M., Vogt, F., Blindt, R., and Gries, T. "Improving the Mechanical Properties of Braided Shape Memory Polymer Stents by Heat Setting," AUTEX Research Journal Vol. 10, No. 3, 2010.

${ }^{13}$ Meng, H., and Hu, J. "A Brief Review of Stimulus-active Polymers Responsive to Thermal, Light, Magnetic, Electric, and Water/Solven Stimuli," Journal of Intelligent Material Systems and Structures Vol. 21, 2010, pp. 859-885.

${ }^{14}$ Anadon, J. "Large Force Shape Memory Alloy Linear Actuator," Department of Mechanical Engineering. Master of Science, University of Florida, 2002, p. 87.

${ }^{15}$ Diehm, C., Trampisch, H. J., Lange, S., and Schmidt, C. "Comparison of leg compression stocking and oral horse-chestnut seed extract therapy in patients with chronic venous insufficiency," The Lancet Vol. 347, No. 8997, 1996, pp. $292-294$.

${ }^{16}$ Doan, B., Kwon, Y.-H., Newton, R., Shim, J., Popper, E., Rogers, R., Bolt, L., Robertson, M., and Kraemer, W. "Evaluation of a lower-body compression garment," Journal of Sports Sciences Vol. 21, 2003, pp. 601-610.

${ }^{17}$ Kragh Jr., J., Littrel, M., Jones, J., Walters, T., Baer, D., Wade, C., and Holcomb, J. "Battle Casualty Survival with Emergency Tourniquet Use to Stop Limb Bleeding," The Journal of Emergency Medicine Vol. ISSN 0736-4679, 2009.

${ }^{18}$ Tourbier, D., Knudsen, J., Hargens, A. R., Tanaka, K., Waldie, J., Webb, P., and Jarvis, C. W. "Physiological Effects of a Mechanical Coutner Pressure Glove," International Conference on Environmental Systems. SAE, Orlando, FL, 2001.

${ }^{19}$ Waldie, J., Tanaka, K., Tourbier, D., Webb, P., Jarvis, C. W., and Hargens, A. R. "Compression under a mechanical counter pressure space suit glove," Journal of Gravitational Physiology Vol. 9, No. 2, 2002, pp. 93-98.

${ }^{20}$ Pitts, B., Brensinger, C., Saleh, J., Carr, C., Schmidt, P., and Newman, D. "Astronaut Bio-Suit for Exploration Class Missions: NIAC Phase I Report." Massachusetts Institute of Technology, Cambridge, MA, 2001.

${ }^{21}$ Bethke, K. "The Second Skin Approach: Skin Strain Field Analysis and Mechanical Counter Pressure Prototyping for Advanced Space Suit Design," Dept. Aeonautics and Astronautics, SM, Massachusetts Institute of Technology, Cambridge, MA, 2005.

${ }^{22}$ Jessiman, A. "Bio-Suit: Smart Materials and Technical Textiles." Mide Technology Corporation, Bio-Suit Advisory Board Workshop, 2004.

${ }^{23}$ Waldie, J. "Mechanical Counter Pressure Space Suits: Advantages, Limitations and Concepts for Martian Exploration." The Mars Society, 2005.

${ }^{24}$ Judnick, D., Newman, D., and Hoffman, J. "Modeling and Testing of a Mechanical Counterpressure Bio-Suit System," International Conference on Environmental Systems 2007-01-3172, 2007.

${ }^{25}$ Rogosic, J. "Bio-Suit Design Analysis and Materials Selection Models: Options for future BioSuit leg segment prototyping." [Unpublished work] Massachusetts Institute of Technology, Cambridge, MA, 2007.

${ }^{26}$ Tanaka, K., Danaher, P., Webb, P., and Hargens, A. R. "Mobility of the Elastic Counterpressure Space Suit Glove," Aviation, Space, and Environmental Medicine Vol. 80, No. 10, 2009, pp. 890-893.

${ }^{27}$ Schmidt, P. "An Investigation of Space Suit Mobility with Applications to EVA Operations." Department of Aeronautics and Astronautics, Ph.D., Massachusetts Institute of Technology, Cambridge, MA, 2001.

${ }^{28}$ Judnick, D. "Modeling and Testing of a Mechanical Counterpressure BioSuit System," Dept. Aeronautics and Astronautics. SM, Massachusetts Institute of Technology, Cambridge, MA, 2007, p. 190.

${ }^{29}$ Annis, J., and Webb, P. "Development of a Space Activity Suit," NASA Contractor Report CR-1892. 1971.

${ }^{30}$ Berzowska, J., and Coelho, M. "Kukkia and Vilkas: Kinetic Electronic Garments," Ninth IEEE International Symposium on Wearable Computers. IEEE, 2005.

${ }^{31}$ Simon, C., Potter, E., McCabe, M., and Baggerman, C. "Smart Fabrics Technology Development: Final Report." NASA Johnson Space Center, Houston, TX, 2010, p. 20.

${ }^{32}$ Tadesse, Y., Thayer, N., and Priya, S. "Tailoring the Response Time of Shape Memory Alloy Wires through Active Cooling and Pre-stress," Journal of Intelligent Material Systems and Structures Vol. 21, No. January 2010, 2009, pp. 19-40.

${ }^{33}$ Escudero, A., Alvarez, J., and Leija, L. "Development and characterisation of electromechanical muscles for driving transhumeral myoelectric prostheses," Prosthetics and Orthotics International Vol. 26, 2002, pp. 226-234.

${ }^{34}$ Bar-Cohen, Y. "Electro-active polymers: current capabilities and challenges," Smart Structures and Materials Symposium. Vol. 4695-02, SPIE, San Diego, CA, 2002. 
${ }^{35}$ Bonser, R. H. C., Harwin, W. S., Hayes, W., Jeronimidis, G., Mitchell, G. R., and Santulli, C. "EAP-Based Artificial Muscles as an Alternative to Space Mechanisms: Final Report." The University of Reading, Reading RG6 2AY, 2004.

${ }^{36}$ Ji, F., Zhu, Y., Hu, J., Liu, Y., Yeung, L.-Y., and Ye, G. "Smart polymer fibers with shape memory effect," Smart Materials and Structures Vol. 15, 2006, pp. 1547-1554.

${ }^{37}$ Kofod, G., Sommer-Larsen, P., Konbluh, R., and Pelrine, R. "Actuation Response of Polyacrylate Dielectric Elastomers," Journal of Intelligent Material Systems and Structures Vol. 14, No. December 2003, 2003, pp. 787-793.

${ }^{38}$ Arora, S., Ghosh, T., and Muth, J. "Dielectric elastomer based prototype fiber actuators," Sensors and Actuators A Vol. 136, 2006, pp. 321-328.

${ }^{39}$ Pelrine, R., Kornbluh, R., Pei, Q., Stanford, S., Oh, S., Eckerle, J., Full, R., Rosenthal, M., and Meijer, K. "Dielectric Elastomer Artificial Muscle Actuators: Toward Biomimetic Motion," Smart Structures and Materials 2002: Electroactive Polymer Actuators and Devices (EAPAD). Vol. 4695, SPIE, 2002, pp. 126-137.

${ }^{40}$ Pelrine, R., Kornbluh, R., Pei, Q., and Joseph, J. "High-Speed Electrically Actuated Elastomers with Strain Greater than $100 \%$," Science Vol. 287, 2000, pp. 836-839.

${ }^{41}$ Plante, J.-S., and Dubowsky, S. "On the Nature of Dielectric Elastomer Actuators and Its Implications for Their Design," Smart Structures and Materials 2006: EAPAD. Vol. 6168, SPIE, 2006, pp. 61681J-1 - 61681J-11.

${ }^{42}$ Wingert, A., Lichter, M., and Dubowsky, S. "On the Design of Large Degree-of-Freedom Digital Mechatronic Devices Based on Bistable Dielectric Elastomer Actuators," IEEE/ASME Transactions on Mechatronics V. 11, No. 4, 2006 , pp. 448-456.

${ }^{43}$ Carpi, F., Bauer, S., and De Rossi, D. "Stretching Dielectric Elastomer Performance," Science 330, 2010, p. $1759-1761$.

${ }^{44}$ Qiao, L., Rimoli, J., Chen, Y., Schuh, C., and Radovitzky, R. "Nonlocal Superelastic Model of Size-Dependent Hardening and Dissipation in Single Crystal Cu-Al-Ni Shape Memory Alloys," Physical Review Letters Vol. 106, 2011 , pp. 085504 1-4.

${ }^{45}$ Johnson, R., Padgett, J., Maragakis, M. E., DesRoches, R., and Saiidi, M. S. "Large scale testing of nitinol shape memory alloy devices for retrofitting of bridges," Smart Materials and Structures Vol. 17, No. 3, 2008.

${ }^{46}$ Yang, K., and Gu, C. L. "A novel robot hand with embedded shape memory alloy actuators," Journal of Mechanical Engineering Science Vol. 216, 2002, pp. 737-745.

${ }^{47}$ Lee, S.-K., Lee, S.-J., An, H.-J., Cha, S.-E., Chang, J. K., Kim, B. K., and Pak, J. J. "Biomedical Applications of Electroactive Polymers and Shape Memory Alloys," Smart Structures and Materials 2002: EAPAD. Vol. 4695, 2002 , pp. 17-31.

${ }^{48}$ Pfeiffer, C., De Laurentis, K., and Mavroidis, C. "Shape memory alloy actuated robot prostheses: initial experiments," 1999 IEEE International Conference on Robotics and Automation. IEEE, Detroit, MI, 1999, pp. 2385-2391.

${ }^{49} \mathrm{Lu}$, A., Grant, D., and Hayward, V. "Design and Comparison of High Strain Shape Memory Alloy Actuators," International Conference on Robotics and Automation. 0-7803-3612-7-4/97, IEEE, Albuquerque, New Mexico, 1997.

${ }^{50}$ Lucas. "Nitinol Wire Experiment," UNICAMP, Brazil, 2008.

${ }^{51}$ Chen, Y., and Schuh, C. "Size effects in shape memory alloy microwires," Acta Materialia Vol. 59, 2010, pp. $537-553$.

${ }^{52}$ Ratna, D., and Karger-Kocis, J. "Recent Advances in Shape Memory Polymers and Composites: A Review," Journal of Materials Science Vol. 43, 2008, pp. 254-269.

${ }^{53}$ El Feninat, F., Laroche, G., Fiset, M., and Mantovani, D. "Shape Memory Materials for Biomedical Applications," Advanced Engineering Materials Vol. 4, No. 3, 2002, pp. 91-104.

${ }^{54}$ Kunzelman, J., Chung, T., Mather, P., and Weder, C. "Shape memory polymers with built-in threshold temperature sensors," Journal of Materials Chemistry Vol. 18, 2008, pp. 1082-1086.

${ }^{55}$ Lan, X., Liu, Y., Lv, H., Wang, X., Leng, J., and Du, S. "Fiber reinforced shape-memory polymer composite and its application in a deployable hinge," Smart Materials and Structures Vol. 18, 2009.

${ }^{56}$ Kamiya, R., Cheeseman, B., Popper, P., and Chou, T.-W. "Some recent advancements in the fabrication and design of three-dimensional textile preforms: a review," Composites Science and Technology Vol. 60, 2000, pp. 33-47.

${ }^{57}$ Demboski, G., and Bogoeva-Gaceva, G. "Textile Structures for Technical Textiles II Part: Types and Features of Textile Assemblies," Bulletin of the Chemists and Technologists of Macedonia Vol. 24, No. 1, 2004, pp. 77-86.

${ }^{58}$ Emery, I. The Primary Structures of Fabrics. Washington, D.C.: The Textile Museum, 1994.

${ }^{59}$ Birkefeld, K., Roder, M., von Reden, T., Bulat, M., and Drechsler, K. "Characterization of Biaxial and Triaxial Braids: Fiber Architecture and Mechanical Properties," Applied Composite Materials Vol. 10.1007/s10443-011-9190-2, 2011.

${ }^{60}$ Ding, N. "Balloon Expandable Braided Stent with Restraint." Patent \#5,899,935, United States, 1999.

${ }^{61}$ Klute, G., and Hannaford, B. "Fatigue Characteristics of McKibben Artificial Muscle Actuators," Proceedings of the 1998 IEEE/RSJ International Conference on Intelligent Robots and Systems. Victoria, B.C., Canada, 1998, pp. 1776-1781.

${ }^{62}$ Wang, B.-R., Jin, Y.-L., and Wei, D. "Modeling of Pneumatic Muscle with Shape Memory Alloy and Braided Sleeve," International Journal of Automation and Computing Vol. 7, No. 3, 2010.

${ }^{63}$ Carpi, F., and De Rossi, D. "Electroactive Polymer-Based Devices for e-Textiles in Biomedicine," IEEE Transactions on Information Technology in Biomedicine Vol. 9, No. 3, 2005, pp. 295-318.

${ }^{64}$ Messidoro, A. "Dielectric Elastomers: Preliminary Assessment as Building Blocks of a Hybrid MCP Space Suit," [Unpublished Work]. Massachusetts Institute of Technology, July, 2012.

${ }^{65}$ Olson, M. "Chinese Finger Cuff Dental Floss." United States Patent \#4817643, 1989.

${ }^{66}$ Techflex. "<http://techflex.com/prod_CCP.asp>," Accessed on September 28, 2011, 2011.

${ }^{67}$ Texgen. "TexGen Applications," <http://texgen.sourceforge.net/> Accessed on December 5, 2011, 2011.

${ }^{68}$ Molnar, D. "Modelling Materiality: Integrating the Design and Specification of Textiles," Graduate School of Design. Harvard, Cambridge, MA, 2012. 